\title{
Producing collaborative public space - The Laboratory of Intervention in Architecture in situ / experiment
}

\author{
Filipa Ramalhete [0000-0002-6/39-7676], Universidade Autónoma de Lisboa, \\ Department of Architecture, and Universidade Nova de Lisboa, \\ Interdisciplinary Centre of Social Sciences, Lisbon, Portugal. framalhete@autonoma.pt
}

\begin{abstract}
This chapter discusses the role of collaborative practices for the production of public spaces. The growing complexity of urban contexts, due to changes in the production model and in urban activities is a challenge for scholars, technicians and residents. In this context collaborative practices have been a common approach in urban interventions in the last decades. The text presents eight editions of the project Laboratory of Intervention in Architecture in situl, from 2012 to 2018. It is a project of intervention in local public spaces with the partnerships of the Municipality of Almada and numerous local institutions, using collaborative practices as methodological approach. In situ/ is also a learning process, as it is coordinated by a research centre, and has a strong concern with the educational aspects of these living labs and with urban research. Different research themes have been addressed - such as informal neighbourhoods, old industrial areas or coastal environmental protection - but they all have a common ground: how can communities (be they academic, local or institutional) contribute to solve territorial problems in transitional urban contexts using public space as a mediation and negotiation tool? In situ/ projects aim to promote innovative teaching and learning experiences outside the academic context, in multidisciplinary and diverse social and cultural contexts, but also to investigate issues of the city in transition and intervene in real contexts of action, promoting diversified partnerships with local entities, designing and building solutions to the challenges of contemporary metropolitan contexts, thus contributing to improve the quality of life of the populations. Along the same lines, this chapter aims to present the laboratories' methodological approach, focusing on the organizational aspects, the importance of all the actors involved and of the learning experience.
\end{abstract}

Keywords - Collaborative practices, architecture, communities of practice, in situ 


\section{INTRODUCTION}

The increasing complexity of urban systems, especially the ones marked by economic or functional crisis - such as the decline of industrial areas or the persistence of slums - together with the increasing globalization of knowledge, are the source of a lively debate about the city as a socially produced and constantly changing space. Territorial problems in transitional urban contexts have been addressed, in the last decades, not only by academics (Lefebvre, 1968, 1986; Ledrut, 1980; Soja, 2010), but also by approaches that place the emphasis on the process and not on the final product, calling for collaborative methodologies that assume that citizens can play an active role in defining and transforming the space in which they live (Healey, 1997 and 2003). Many of these interventions are concentrated on the public space, which has been the center of an intensive debate, focused on its importance for communities' identity reinforcement, but also as a place for negotiation, between citizens and authorities (Delgado, 20I I), often debating the contradictions between identity narratives and formal normative (Carmona, 20I5).

Interventions in several territories have multiplied in recent decades, especially those of exclusion or resulting from processes of loss of urban vitality (for example in UN-HABITAT, 20I0). Many of these actions tend to be a collective response to public policies concerning public space, often criticized for their top-down approaches (Carmona, 20I5). However, given the diversity of spaces and contexts, these interventions tend to emphasize the particularities of each experience, with some difficulties in objectifying and systematizing concepts and practices. At the same time that terms like "participation" and "collaboration" are trivialized, the underlying question remains regarding a clear definition of the boundaries and scope of these concepts (Ramalhete, Gato, 2016). As such, and in the context of this text, it is relevant to introduce the concept of "community of practice" and explore its definition and scope. This concept was first used by the anthropologist Jean Lave and the computer scientist Etienne Wenger in 1991, in the book "Situated Learning: Legitimate Peripheral Participation" defending that communities are situated social learning systems. The conceptual and empirical framework for this notion has been developed since then, and a more recent definition for it is: "Communities of practice are formed by people who engage in a process of collective learning in a shared domain of human endeavor: a tribe learning to survive, a band of artists seeking new forms of expression, a group of engineers working on similar problems, a clique of pupils defining their identity in the school, a network of surgeons exploring new techniques, a gathering of first-time managers helping each other cope."' (Wenger-Trayner, 20I5). Concerning in situ/ this concept is especially relevant, since it is centred on the process of learning and on the construction of something that results from a collaborative learning process, where the final construction is much more than the sum of the parts of each one enrolled. 
In the case of architectural intervention projects, the term "community" has been used in projects that are essentially defined as being interventions of proximity, with a greater or lesser degree of interaction with local agents, with an almost indiscriminate appropriation of the term. In a relationship of close complementarity with the term "community", there is also the term "agency", since the logic behind these projects is based on the premise that actors have the capacity to intervene in the socio-cultural structure, promoting active involvement. Recently, the term spatial agency, created in the scope of a research project at the University of Sheffield ${ }^{2}$ (Awan, Schneider, Till, 20I I), emphasized the transforming capacity of architecture as a discipline of action in addition to the design and production of buildings (Schneider, Till, 2009). The project analysed and gave visibility to intervention initiatives by architects from several urban communities, many of whom inspired by the approaches of participatory interventions in the public space, derived from the perspective of sustainable planning of proximity and collaboration, based on the principle and theory of subsidiarity of the 1990s (Águas, 2012; Aguilera, 2004, Remesar, 2003; Borja, Muxi, 2003). In many of these projects public space is assumed as a transactional space, of social transformation and integration, and the produced objects themselves are considered producers of a transforming agency (Gato, Ramalhete, Vicente, 2016; Gell, 1998). In many circumstances, actions are taken aside formal land-use plans, although not necessary against them and become a matter of thought for future public space policies. In these cases, public space is also an experimental, learning space, with the negotiable capability of testing spatial hypothesis that may be, afterwards, consistently adopted as solutions.

This chapter has two main goals: i) to contribute to the debate on the role of collaborative communitarian projects as proposals to discuss the territories' futures. The text advocates that projects such as in situ/ are valid methodologies to analyse and test transitional or temporary uses for territories under discussion; ii) to discuss the importance of collaborative processes such as in situ/ as learning experiences. Since in situ/ is an academic project, based on students' participation, which contributes to a collaborative process with local agents, creating communities of practice, it is important to show that the final conclusion results from a collaborative learning process.

\section{IN SITU/ LABORATORIES: METHODOLOGY}

This chapter describes a case study of a laboratorial experiment regarding public space interventions in complex and transitory urban contexts. The project described places strong emphasis on the collaborative nature of the process, which includes co-creation with a large range of participants (inhabitants, local organizations, municipality staff and politicians, students, researchers, professionals, policy makers). 
In situ/ assumes itself as a project which has been able to create collaborative communities of practice, as methodological approach.

The Laboratories of Intervention in Architecture in situ/ are research/action projects that aim to promote innovative teaching and learning experiences outside the academic context, by investigating problems of the city in transition and intervening in real contexts of action.

Since 2012, eight editions have been held, all in the municipality of Almada, Portugal. The first edition was held in Terras da Costa, as part of a research project on that neighbourhood ${ }^{3}$. Following this edition, a partnership was established with the Department of Urban Planning of the Municipality of Almada (CMA). In the following editions, the intervention sites were selected together with the CMA team, always keeping, as selection criterion, spaces with intervention needs or in the process of transition without defined new uses, either in short-term interventions, or in terms of territorial management instruments. In fact, sometimes the existing or under development instruments do not address the issues raised by the territories - due to either the slow planning processes or the inadequacy of their proposals to the socio-economic reality of recent years. As a result, laboratories in situ/ always seek to propose reflections and transition solutions, providing and opening possibilities and immediate uses, regardless of interventions that may be made in the future. Throughout the various editions, a methodology of approach and intervention was designed, which is systematized next. All the editions promoted diversified partnerships with local entities, contributing to improve not only the spaces themselves, but also the populations' quality of life.

With regard to working methodologies, CEACT has maintained an organization team of three people (two architects, one anthropologist) throughout the various in situ/ editions, but each one has, as a rule, one or more teams of invited tutoring architects. The criteria for invitation are young architects, with experience in design and construction, and with works whose quality and interest meet the challenges proposed in each edition. The Laboratories are prepared six months to one year in advance, in articulation with the tutoring team, establishing also the necessary partnerships, site visits, meetings and contacts with the team from the CMA and other local partners. It is also during this period that possible programs for the intervention site and the building materials to be used are discussed and defined (through CMA support, direct procurement or sponsorship). Albeit with some differences among the various editions, the laboratories are usually performed within a period of about two weeks, comprising a design moment and a construction time. These are very intense experiences, for tutors and participants alike. The construction dynamics and the materials used vary, but this is an essentially collaborative process, with the participation of students, volunteers, residents, tutors, as well as technical and operational staff from the CMA.

${ }^{3}$ Project Fronteiras Urbanas (FCT PTDC/CPE-CED/I 19695/2010). 
Although the outcomes are always different, it is important to highlight the following aspects: I) the experimental side of these learning / teaching experiences, which include a place for research and experimentation, but also for error; 2) the goal is not to build perennial structures, but rather to think of the territory and to build possibilities, sometimes transitory (which, of course, does not imply compromising the quality of the project or constructions); 3 ) in situ/ is not presented to the partners as a "participant" or "community" project, but as an experience with a limited duration of collaborative work. In fact, the creation of a "community of practice" is fostered, in which diverse actors (students, tutors, and associations, population, technical and operational from the municipality...) gather and work on a common project for a common space, based on operational cohesion and a methodological approach that has been developed and adapted over the years; 4) all the initiatives were held in public or common spaces, assuming that these have a transformation potential and are the place for promoting the discussion about the future role of those territories. In all eight editions, around 350 participants were involved, in addition to partners, speakers (as there are always conferences during the laboratory), residents, members of the organization and tutors. As indicated, each in situ/ edition has presented different challenges. However, they have all posed contemporary urban problems to the tutors and participants. This diversity was intentional, since, from the academic, pedagogical and laboratorial point of view, it is important not to focus on just one reality. On the other hand, the reduced temporality of the in situ/ does not allow, admittedly, definitive solutions. The challenge is precisely to open possibilities, to design and to construct hypotheses for spaces that are, in fact, challenges for which there are not always immediate solutions.

These aspects may be considered limitations to the scope and durability of the interventions. However, the fact that the methodology has been coherent over eight editions has made it possible to go beyond these limits in several dimensions: e.g., it has been possible to identify logical communication among the various actors (organization, municipality, associations, participants, residents), some already present for several editions. This corresponds to a continuous process of mediation among the various agents, but the overall goals of the Laboratories ensure continuity, thus crea-ting a common culture, reinforced with each edition by the continuity of the project.

One interesting aspect is that the objects built are always a trigger for new spatial dynamics that start during the construction process, with the interaction between the participants and area's dwellers or passers-by. There is also a strong emphasis on the experimental side of each edition. Not only from the constructive point of view, since the participants are trying construction solutions that can be built with their own hands and available means (limited time, limited materials, limited skills), but also because each project experiments a solution for the problems raised by each territory. 
The goal of all the laboratories is to build some kind of structures in public areas. These structures are a product of the whole collaborative process, from logistic preparation and territory analysis to the final construction. Nevertheless, the items built are proposals for temporary uses or hypotheses for future solutions, rather than definite solutions. The final design is not only a synthesis made by students and tutors of all the contributions and data gathered, with the participation of all the local actors, but a product of a learning experience as well.

\section{IN SITU/LABORATORIES: AN OVERVIEW}

All the Laboratories have taken place in Almada, and (except for the 2013 and 2014 ones) in other places, addressing different challenges ${ }^{4}$. One of the main objectives of the first editions was to think about urban contexts of informal genesis (Noutra Costa - Terras da Costa da Caparica, in 2012, InSitu e INSITUaction, in Torrão 2, Trafaria - 20I3 and 20I4). In the first edition, which had six teams of tutors ${ }^{5}$, the exercise was mainly theoretical and speculative, focusing on the need to solve - in the short or medium term - the precarious living conditions of the Terras da Costa neighbourhood following an approach starting from the analysis of common space as a common ground for solving housing problems. The only construction was an artistic installation built in one afternoon by Likearchitects. From this exercise (Fig. I), however, new dynamics emerged, which led, for example, to the later construction of a communal kitchen (Ateliermob + Warehouse).

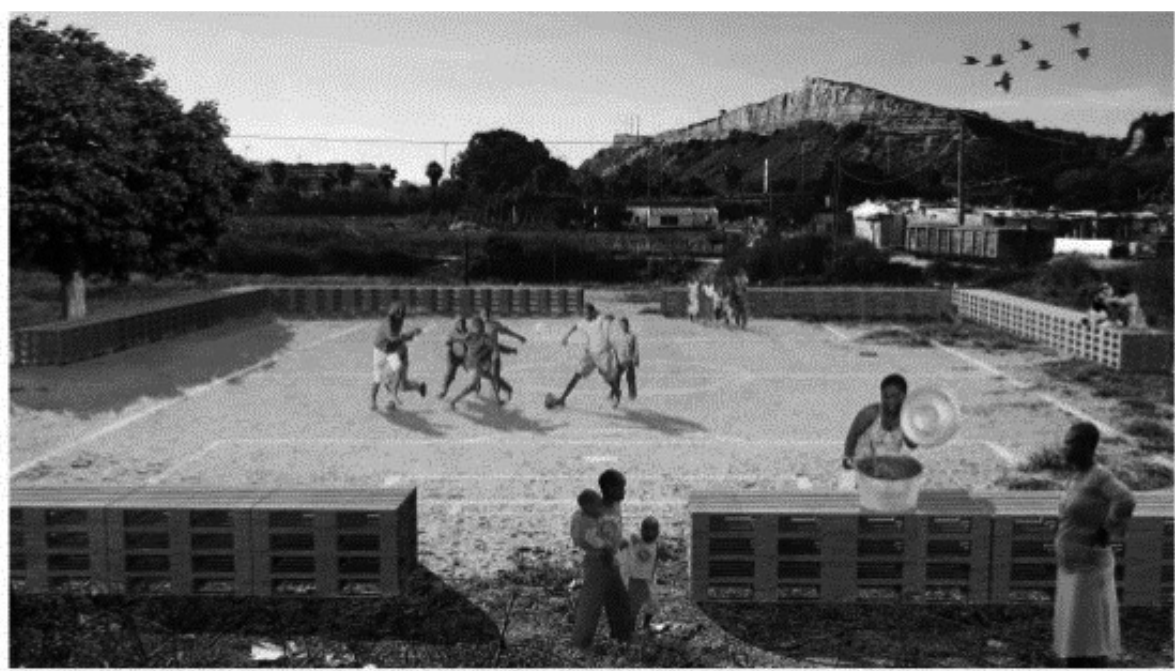

Fig. I: Noutra Costa: ateliermob proposal for a common initiative for future projects. Source: Author, 2012.

\footnotetext{
${ }^{4}$ For the in situ/ website, see http://insitu.autonoma.pt/. For a short video, go to https://www.youtube.com/watch?v= OlmDWmjCR34\&feature=youtu.be. For a deeper analysis see Ramalhete et al (2020).

${ }^{5}$ Argot, Atelierbase, Ateliermob, José Castro Caldas + Sérgio Silva, Likearchitects, OTO.
} 
As a result of the partnership established during Noutra Costa, the coordination and the $\mathrm{CMA}^{6}$ teams proposed a different challenge for the following year: to think and build structures to support the population of the Torrão 2 neighbourhood. In Torrão 2, the Laboratory addressed some of the basic problems of the neighbourhood's public space (insufficient collection of waste, lack of safe spaces for children to play, lack of public facilities, degradation of the space of the residents' association). The teams of tutors ${ }^{7}$ worked with the students and with the collaboration of the residents, to design and test solutions for these problems, such as the construction of garbage collection points, a children's playground, structures to support local vegetable gardens, the renovation of the residents' association building, and the construction of an outdoor table in a public space (Fig. 2), with the purpose of qualifying the places where children and youngsters met.

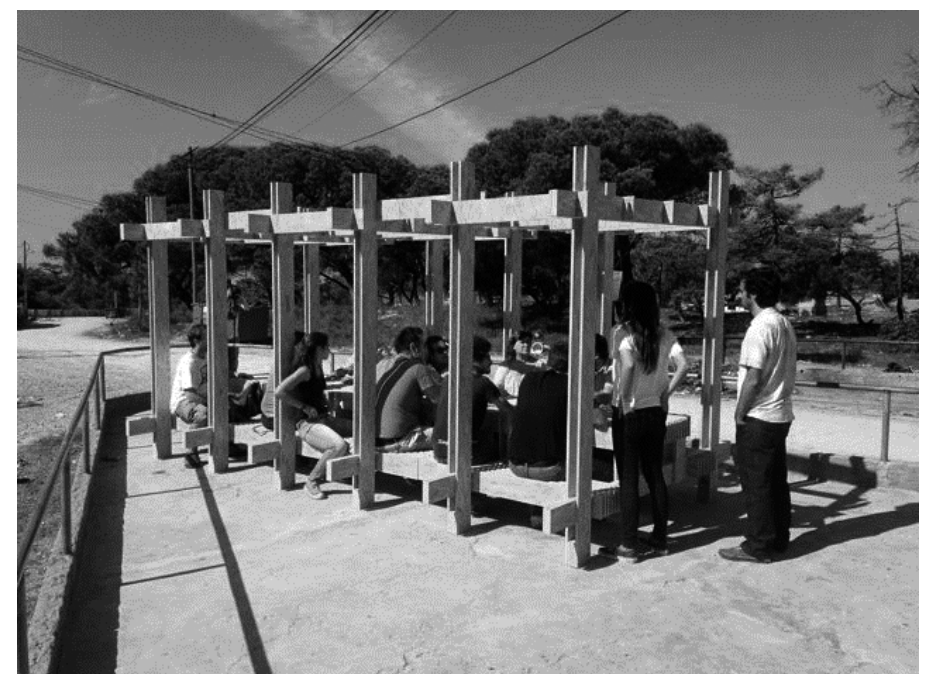

Fig. 2: Building a communitarian table at Torrão 2. Photo: Likearchitects, 2013.

Due to the social and urban complexity of Torrão 2 , is was decided to continue working in the same territory in 20l4, with the goal of improving, on a more permanent basis, two of the spaces worked in the previous year. The playground was rebuilt (Fig. 3), and an outdoor gymnasium plus a public space with shade were created $^{8}$. Regarding these first three laboratories (Ramalhete; Silva, 2014) it is important to emphasize the significant interaction with the population and a growing participation by the CMA, as well as the fact that, in parallel or as a consequence of in situ/, several interventions in the neighbourhood's public spaces have taken place since then, either by private initiative or by local associations.

\footnotetext{
${ }^{6}$ Filipa Ramalhete, Pedro Campos Costa, Sérgio Silva (CEACT), Alexandra Paio and Bárbara Varela (Vitruvius FabLab, ISCTE/IUL), Paulo Pardelha, Ricardo Carneiro and Amélia Pardal (CMA) - 2013 edition; José Castro Caldas (CEACT) was added in the 2014 edition.

${ }^{7}$ The teams of tutors were A+ LBY architects, Argot + I/2atelier, Atelierbase, Ateliermob and Likearchitects.

${ }^{8}$ Miguel Marcelino and João Boto Caeiro + Rita Sarzedas were the tutors in 2013.
} 


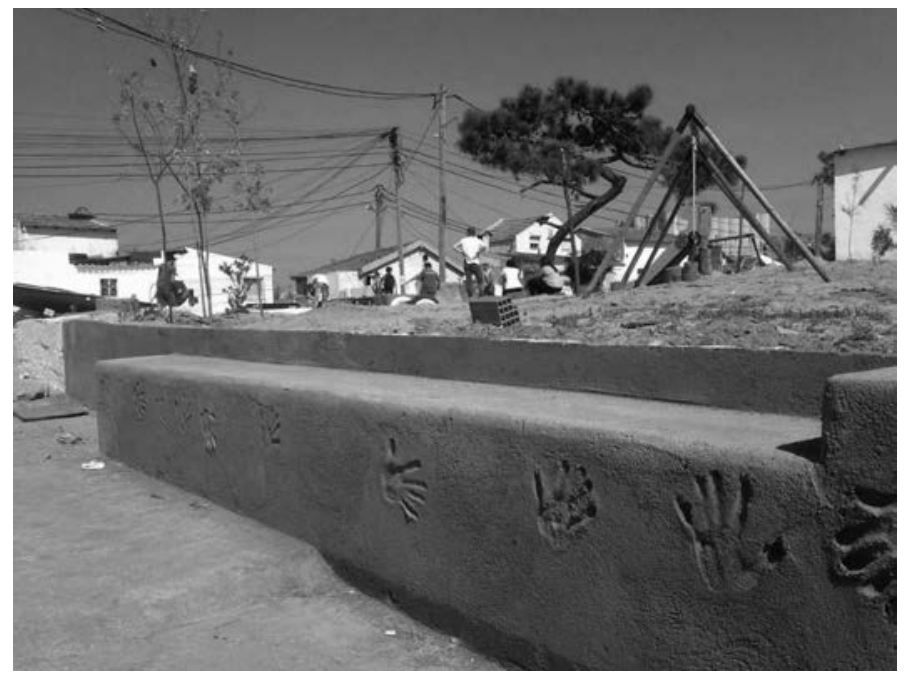

Fig. 3: Improving the playground at Torrão 2. Photo: Miguel Marcelino, 2014.

After the previous experiences of working in open public spaces, with strong interaction with the local community, the 2015 edition embraced a distinct challenge: to work in close partnership with two local associations on the theme of heritage rehabilitation. The APPACDM (Portuguese Parents and Friends Association of Citizens with Mental Disability) owns a farm in Pêra, Caparica, where there is a traditional noria the well of which needed repair (Fig. 4). With the collaboration with the Almada Archaeological Centre and the sponsorship of a local ${ }^{9}$ company,

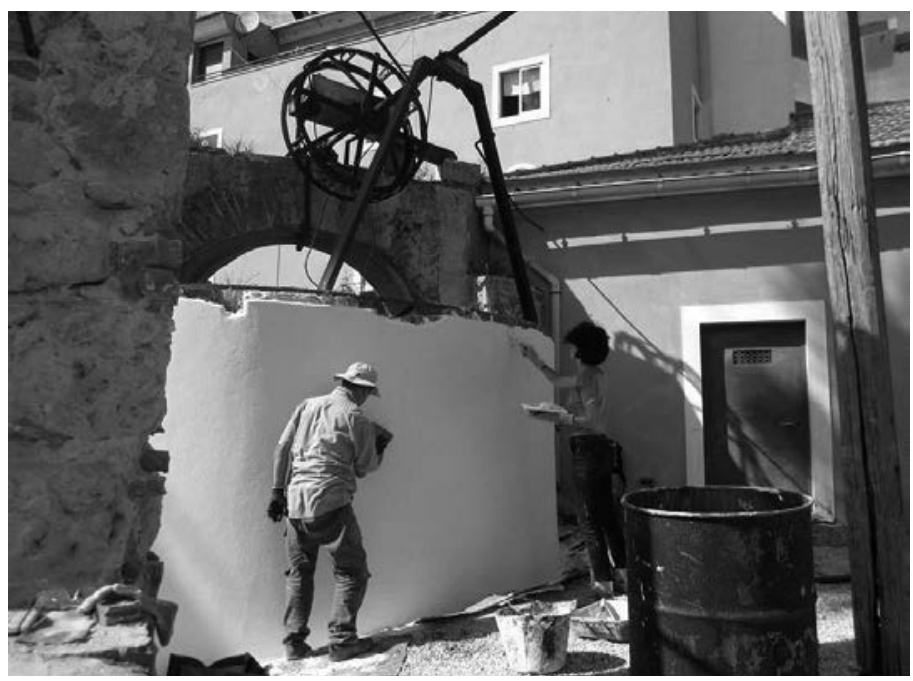

Fig. 4: Learning how to restore a noria with traditional whitewash techniques. Photo: Author, 2015.

\footnotetext{
${ }^{9}$ The coordination of this and the following editions is managed by Filipa Ramalhete, José Castro Caldas and Sérgio Silva. The Centre of Archaeology of Almada has been a partner in the editions after 2015.
} 
Fradical, it was possible to carry out this work, using traditional materials and techniques. Through the Laboratory ${ }^{10}$ some improved structures of the exterior spaces were constructed (Ramalhete; Silva, 2016; ArchDaily Brasil, 2016). In this edition, the interaction between the participants and the users and residents of this Association was particularly interesting, as a very stimulating and participated discussion took place regarding the use of open-air common spaces.

The following year was a particulate intense one, since two in situ/ laboratories took place, both of which as a result of challenges that were launched to CEACT/UAL. In February 2016, INSITU'5" resulted from a challenge launched by the CMA, which was designed to construct blocks (mobile objects that could form barriers in places banned from visiting) and a support structure to visit the facilities of the Trafaria Prison, with the aim of converting that former prison into an area for cultural activities (Baratto, 2017). The structure that was built has provided support for several temporary exhibitions. The constraints in terms of deadlines and weather conditions were the main challenges of this edition. Coordinating resources and the knowledge of all the partners involved, however, allowed us to achieve quite satisfactory results (Fig. 5).

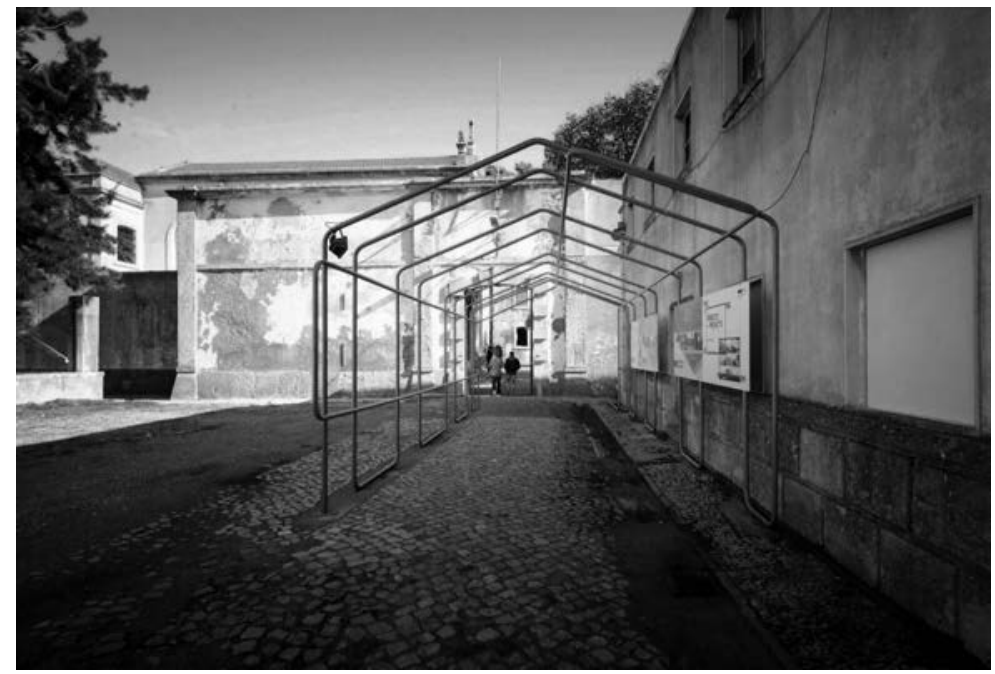

Fig. 5: Building visitation structures in Trafaria Prison. Photo: Author, 2016.

A second project was started in 2016 , scheduled for two years, responding to a need already identified in previous editions. Following an invitation from the 2017 Greenfest festival organisers to design and build a space for meetings and conferences, it was decided, in partnership with the CMA, to begin designing a public space in a derelict

\footnotetext{
${ }^{10}$ Tutored by João Quintela + Tim Simon, Victor Beiramar Diniz and José Castro Caldas.

"Gonçalo Pacheco, José Castro Caldas, Sérgio Silva were the tutors of this edition, held with the direct participation of CMA technicians and operatives.
} 
industrial area, the Caramujo-Romeira. Work was developed in that space ${ }^{12}$, beginning by evaluating the problems and potential of the space, while the (temporary) structure was designed to be placed for the Greenfest. At the location, an urban intervention was made using graffiti, which paved the way for this year's edition. Held in $2017^{13}$, following the topic planned the previous year about vacated industrial spaces and their transitions of possible uses, a proposal for a public space was prepared and implemented, creating a structure that aimed to open new possibilities of usage for that place (Fig. 6).

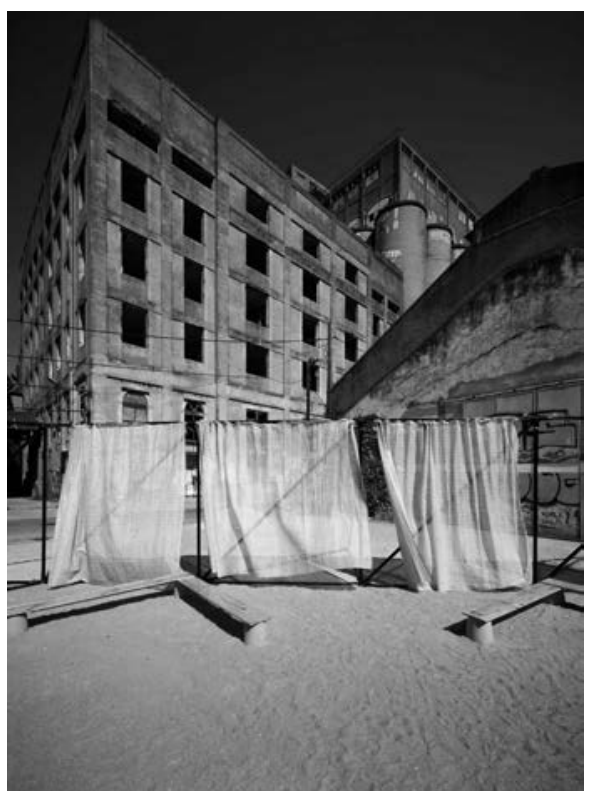

Fig. 6: Creating new public space in Caramujo-Romeira. Photo: Author, 2017.

Finally, the 2017 in situ/ edition responded to an invitation from a local association (EDA - Ensaios e Diálogos) to collaborate with the project TransforMar, for the coastal protection of Cova do Vapor beach. Adjacent to an informal neighbourhood, established in the confluence of the river Tagus with the Atlantic Ocean, this beach suffers from severe erosion, due to considerable human pressure, aggravated by the fact that it's located in a natural high-risk area. Based on the analyses made by local partnerships and tutors ${ }^{14}$, in situ/ built several wood structures to help protecting the dunes from erosion (Fig. 7).

This description concludes the summary of the first eight editions of in situ/. It is important to stress that, due to the limited time and financial resources of these projects, it hasn't been possible to make a parallel process of evaluation, to know in

\footnotetext{
${ }^{12}$ Under the tutoring of Rita Aguiar Rodrigues and Joana Pestana.

${ }^{13}$ Under the tutoring of ForStudio.

${ }^{14}$ Girão Lima Arquitectos and Eduardo Conceição.
} 


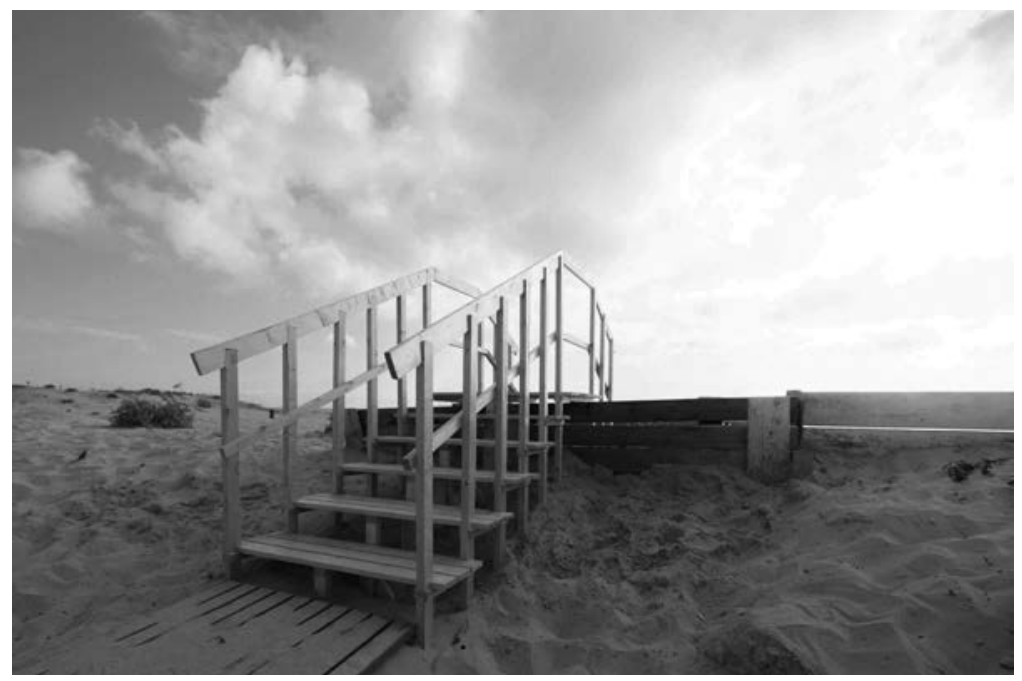

Fig. 7: Protecting the dunes at Cova do Vapor. Photo: Author, 2018.

depth the strategies and the benefits, direct or indirect, of each edition. Nevertheless, an internal evaluation is done after each edition and, since some years have passed already, some results are visible.

\section{DISCUSSION AND CONCLUSIONS}

In the past decades public space has been one of the most studied topics for the disciplines concerned with spatial studies, such as sociology, anthropology or urbanism. Regardless of each author's academic, political or ideological approach, there is a broad consensus that public space is not a tabula rasa, but rather a social product (Lefebvre, 1986; Ledrut, 1980). The project presented here, the in situ/ laboratories, follows the approaches defended by authors such as Delgado (20II) and Soja (2010), assuming that public space is where social negotiation takes place, since it is also where conflicts emerge and where social and spatial transformation is claimed. In this sense, in situ/ was conceived as a space where there is room for thought, experimentation, and mediation between all actors, having as basic premise that the role of each actor is relevant to the construction of the final objects. In this context, it is interesting to notice that the final results are more than the sum of the parts, reflecting processes of mediation, learning, negotiation and collaboration among all the players, thus accepting the assumptions of space agency (Schneider, Till, 2009), since it has been observed, after each edition, that the intervened spaces and constructed objects have in themselves a transforming capacity (it is relevant that none of the objects has been destroyed or vandalized).

Although the territorial contexts and the results were different in each edition, it is important to highlight two aspects: I) the laboratorial aspect - since in situ/ is part of an academic learning experience, research is essential, but participants also have 
the opportunity to build what they conceive, and there is also margin for error; 2 ) the goal is not to build perennial structures, but rather to think about the territory and to build possibilities, sometimes transitory (which, of course, does not imply compromising the quality of the project or constructions), for what the places can be.

As stated above, in all eight editions of in situ/, around 300 participants were involved, in addition to the partners, speakers, residents, members of the organization and tutors. The goals of all laboratories have been fully achieved, not only from the point of view of academic learning goals, but also from the viewpoint of the intervention/ construction and mediation with the partners involved in each edition, providing participants with a social and architectural experience. By building solutions with their own hands, students gain a material perception of space, and also discover the need for mediation processes.

As discussed, each in situ/ edition has presented different challenges. However, they all posed contemporary urban problems to the tutors and participants. This diversity was intentional, since, from the academic, pedagogical and laboratorial point of view, it is important not to focus on just one reality. On the other hand, the reduced temporality of in situ/ does not allow, admittedly, definitive solutions. The challenge is precisely to open possibilities, to design and to construct hypotheses for spaces that are, in fact, challenges for which there are not always immediate solutions.

The fact that the methodological approach of in situ/ has remained coherent over eight editions has made it possible to identify a logical communication among the various actors (organization, municipality, associations, participants, residents), some already present for several editions. This corresponds to a continuous process of mediation among the various agents, some of whom remain (like the CMA team) while others are always different (e.g. tutors); still, the overall goals of the Laboratories ensure continuity, creating a culture common to all issues. This common culture, reinforced with each edition by the continuity of the project, is aimed at creating communities of practice that have guaranteed the success of each Laboratory. Moreover, one aspect that has been interesting is that laboratories help to strengthen communication between people living in these territories and public institutions, contributing to a better understanding of the mutual realities and building new perceptions about the intervened territories. Finally, another finding relates to the impacts: in the short term, the Laboratories have a very positive impact on those who worked directly on the design and construction. But it has also been seen that the interventions already been carried out, even the most perennial, have a very reasonable durability and seem "to make waves", sparking debates on the territories and originating subsequent projects, with or without a direct relation with in situ/. In the case of Torrão 2, for example, the residents continued the constructions beyond the schedule of the Laboratory. 
In situ/ laboratories combine a practical, workshop, dimension with a research one. The eight editions held until 2019 have tested and proven the value of applying the described methodology with consistency over the years. Another relevant contribution from these experiences is that collaborative processes are an interesting and proactive way to discuss and test the future of territories in transition or in deprivation. Also, as learning and teaching experiences, in situ/ laboratories are quite innovative, as they operate in real contexts, solving real problems. Finally, reference should be made to the contribution that these initiatives can represent to the discussion of future models of collaborative planning, not only in contexts of urban continuity, but also in contexts of crisis and uncertainty. These can be debates on the future uses of territories in transition, where these projects could be a way of opening up the discussion about the possibilities that each territory holds to all local agents. The experiments presented have, nevertheless, some limitations. The short temporality of the laboratories implies very intensive work, which does not leave much room for gathering fieldwork data and systematic observation. And, although there is an informal evaluation and follow-up after the laboratories, a systematic evaluation has not been made yet, thus hindering a deeper theoretical and conceptual analysis. In the future, it would also be extremely interesting to promote research on these projects made by other researchers, coming from different knowledge areas. This has happened, on a limited basis, to some of the laboratories, but not to the process as a whole.

\section{REFERENCES}

Águas, S. (2012). Do Design ao Co-Design: uma oportunidade de design participativo na transformação do espaço público. On the W@terfront. 22, 57-70.

Aguilera, F. G. (2004). Arte, Ciudadanía y Espacio Público. In On the W@terfront. 5, 36-5I.

Baratto, R. (2017). Intervenção Arquitetônica propõe a reapropriação de um antigo presídio em Portugal. ArchDaily Brasil. Retrieved from: http://www.archdaily.com.br/br/876890/intervencaoarquitetonica-propoe-a-reapropriacao-de-um-antigo-presidio-em-portugal

Borja, J. \& Muxí, Z. (2003). El espacio público. Ciudad y ciudadanía. Barcelona: Diputación de Barcelona. Carmona, M. (2015). Re-theorising contemporary public space: a new narrative and a new normative. Journal of Urbanism: International Research on Placemaking and Urban Sustainability. 8:4, 373-405.

Delgado, M. (20I I). El espacio publico como ideologia. Madrid: Catarata.

Gato, M. A.; Ramalhete, F. \& Vicente, S. (2013). Hoje somos nós os escultores! Agencialidade e arte pública participada em Almada. Cadernos de Arte e Antropologia (8) I, 53-7I.

Gell, A. (1998). Art and Agency: An Anthropological Theory. Oxford: Oxford University Press.

Healey, P. (1997). Collaborative Planning. Shaping Places in Fragmented Societies. London: MacMillan Press.

Healey, P. (2003). Collaborative Planning in Perspective. Planning Theory. 2: I0 I- I23. University of Newcastle upon Tyne, UK. Retrieved from: http://isites.harvard.edu/fs/docs/icb.topic233853.files/February_ 4-6/Healey_Collaborative.pdf

INSITU / Atelier JQTS. (2016). Retrieved from: http://www.archdaily.com.br/br/792389/insitu-atelier-jqts 
Ledrut, R. (1980). Espaces et Sociétés. Espaces et Sociétés. 34-35: 3-I2.

Lefebvre, H. (1968). Le droit à la ville. Paris: Anthropos.

Lefebvre, H. (1986). La prodution de l'espace. Paris: Anthropos (orig. ed. 1974).

Ramalhete, F.; Silva, S.; Caldas, J.C. \& Quintela, J. (2020). in situ/ Laboratórios de Intervenção em Arquitetura 2012-2019. Lisboa: Universidade Autónoma de Lisboa.

Ramalhete, F. \& Gato, M. A. (2016). Um exercício de reflexão sobre o monumento em discurso direto. In Vicente, Sérgio (coord.) Cidadão escultor escultor cidadão: um monumento à multiculturalidade em Almada. Lisboa: Faculdade de Belas Artes, Universidade de Lisboa: 25-38.

Ramalhete, F. \& Silva, S. (2016). Reabilitação colaborativa: a experiência do Laboratório de Intervenção em Arquitetura INSITU'I5. Atas do Congresso Ibero-Americano "Património, suas matérias e imatérias", Lisboa: LNEC, 2/3 de novembro de 2016.

Ramalhete, F. \& Silva, S. (2014). Intervenções arquitetónicas em espaços informais. estudoprevio 5/6, Lisboa: CEACT/UAL - Centro de Estudos de Arquitetura, Cidade e Território da Universidade Autónoma de Lisboa, 2016. Retrieved from: http://www.estudoprevio.net/artigos/43/filipa-ramalhetesergio-silva---intervencoes-arquitetonicas-em-espacos-informais

Remesar, A. (2003). Arte e Espaço Público. Singularidades e Incapacidades da Linguagem escultórica para o Projecto Urbano. In P. Brandão \& A. Remesar (Eds.) Design de Espaço Público: Deslocação e Proximidade, Lisboa: Centro Português de Design, 26-40.

Schneider, T. \& Till, J. (2009). Beyond Discourse: Notes on Spatial Agency. Agency in Architecture: Reframing Criticality. In Theory and Practice, Spring 2009: 97-III.

Soja, E. W. (2010). Seeking spatial justice. Minneapolis: University of Minnesota Press.

United Nations Human Settlements Programme (UN-HABITAT) (2010). Count me in, Surveying for tenure security and urban land management. Nairobi: UNON/Publishing Services Section.

Wenger-Trayner, E. \& Wenger-Trayner, B. (2015). Introduction to communities of practice A brief overview of the concept and its uses. Retrieved from: http://wenger-trayner.com/introduction-tocommunities-of-practice/. 